\title{
Una colección de entremeses inédita y desconocida (con la edición de La cabeza encantada)
}

\author{
ABRAHAM MADROÑAL*
}

\section{Preliminar}

No suelen abundar las nuevas colecciones de manuscritos que nos ofrezcan entremeses, aunque algunas hemos conocido en fecha reciente. Por eso es más curiosa todavía la existencia de un manuscrito encuadernado en pergamino que recoge veinticuatro entremeses, algunos de ellos desconocidos del todo y otros solo conocidos en versiones diferentes de los que encontramos aquí. El nuevo códice se titula Ramillete divertido y tiene una fecha concreta: $1754^{1}$. En esa fecha se recopila el libro, acaso no con la intención de que se publicara, pues no conserva preliminares de ningún tipo, sino con la de servir de auxilio a quienes querían hacer representaciones particulares y no contaban con demasiados actores. No en vano, en su portada se advierte: El Ramillete divertido, entremeses de varios ingenios y de los más curiosos, propios para ejecutarse en casas particulares, donde no es fácil ejecutar piezas que requieren muchos interlocutores y teatro. La recopilación seguía la senda de un buen número de colecciones de entremeses que han llegado hasta nosotros. Dentro de este nuevo conjunto de entremeses, encontramos una pieza desconocida de indudable inspiración cervantina: La cabeza encantada.

\section{Del Ramillete gracioso al Ramillete divertido}

Una de las primeras antologías entremesiles compuestas de nuevo cuño es la recopilación Ramillete gracioso (Valencia, Silvestre Esparsa, 1643)². Es cierto

* Universidad de Ginebra-CSIC.

1. El libro se encuentra en una biblioteca particular, a la que hemos tenido acceso y a cuyo propietarios agradecemos la deferencia de facilitarnos su consulta.

2. Curiosamente, desconocida para ese gran estudioso de la pieza breve que fue don Emilio Cotarelo y Mori [1911]. 
que la primera de todas las antologías de varios autores había sido Entremeses nuevos (1640), pero esta recopilación no hace sino independizar los entremeses de las comedias con que había aparecido unos años antes con el título de Segunda parte de comedias de Tirso de Molina (1635). Muy poco tiempo después, en 1638, el autor de más éxito en la composición de entremeses, el toledano Luis Quiñones de Benavente, concibe la idea de antologar los suyos en un libro, que por avatares del destino tardaría siete años en ver la luz: la Jocoseria (Madrid, 1645), donde recoge cuarenta y ocho piezas propias. Entre tanto, Francisco Navarrete y Ribera, que se sitúa en el polo opuesto del de Quiñones, porque no había conseguido representar sus obras, se ve obligado a darlas a la imprenta con el título de Flor de sainetes (Madrid, Catalina del Barrio y Angulo, 1640). Las antologías recibían floridos y agradables títulos, como muestra la segunda de las de varios autores en orden cronológico, la titula Donaires del gusto (quizá de 1642, aunque nada nos impide pensar que comparte la fecha de 1643 con la primera recopilación de que hemos hablado). Del año siguiente son la que nos sirve para abrir el epígrafe y Entremeses nuevos (Alcalá: Francisco Ropero, 1643).

Empezaban así las antologías de entremeses, que tuvieron un éxito extraordinario, a tenor de la frecuencia con que se imprimen, por lo menos hasta la última que conocemos, la mencionada Ramillete divertido (1754) a la que pertenece el entremés que nos ocupa hoy. En ese siglo largo se imprimen no menos de cincuenta colecciones, que integran diferente número de piezas y que responden a dos criterios básicos de ordenación: piezas de un solo autor que imprime sus entremeses selectos o antologías de piezas varios autores que recopila un editor. Posteriormente se suceden, entre otras, Entremeses y flor de sainetes (1657), Teatro poético (1658), Musa entretenida, de Coelho Rebelho (1658), Laurel de entremeses (1660), Rasgos del ocio ( $1^{\mathrm{a}}$ parte, 1661; $2^{\mathrm{a}}$, 1664), Tardes apacibles (1663), Donaires de Tersícore de V. Suárez Deza(1 $1^{\mathrm{a}}$, 1663), Ociosidad entretenida (1668), Verdores del Parnaso (1668), Parnaso nuevo (1 $\left.{ }^{\mathrm{a}}, 1670\right)$, Ramillete de sainetes (1672), Sainetes y entremeses, de Gil López de Armesto (1674), Vergel de entremeses (1675), Flor de entremeses (1676), Mejor flor de entremeses (1679), Floresta de entremeses (1680), Jardín ameno (1684), Pensil ameno (1691), Arcadia de entremeses (1691), Verdores del Parnaso de Armesto y Castro (1697), Manojito de entremeses (1700), además de algunas recopilaciones sin año.

Las antologías de entremeses decrecen notablemente en el siglo XVIII, pero aún hay que señalar algunas buenas recopilaciones de uno o varios autores, como las dos de Francisco de Castro Alegría cómica (1702) y Cómico festejo (1742), las Obras poéticas póstumas, de León Marchante (1722), las Comedias nuevas de Antonio de Zamora (1722), la reedición de Arcadia de entremeses (1723) o los Chistes del gusto (1742). La última de esas recopilaciones, según los datos que tenemos actualmente, es esta del Ramillete divertido (1754) muy cerca ya, como se ve, de la fecha de prohibición de los entremeses. 


\section{La antología Ramillete divertido (1754)}

El libro se presenta como un volumen en cuarto, de $215 \times 155 \mathrm{~mm}$., escrito enteramente por una sola mano, que corresponde a la fecha mencionada. En su tejuelo se lee: "ENTRE / MESES / manus / critos". Sus hojas presentan una filigrana con una leyenda, de donde solo podemos deducir que quizá el papel se fabricó en Zaragoza. No presenta, salvo excepciones, tachaduras ni notas marginales de ningún tipo. Se encuentra encuadernado en pergamino, con 148 folios útiles y provisto de una portada que dice:

El Ramillete divertido, / entremeses / de varios ingenios y / de los más curiosos, propios / para ejecutarse en casas / particulares, donde no es / fácil ejecutar piezas que / requieren muchos interlo- / cutores y teatro. / Los recogió y copió un / curioso. / En Madrid, año de 1754.

Como indica esta, se trata de una antología hecha con el fin específico de los entremeses se puedan representar en casas particulares y con pocos actores. No parece que estuviera destinada, al menos en un principio, a la publicación, porque carece de preliminares, con la excepción de una "Tabla de los entremeses contenidos en este libro", que ocupa las dos hojas que siguen a la portada reproducida. Los entremeses empiezan a continuación y con ellos la paginación en números árabes desde el 1 al 148v .

Algunos nombres de poseedores del libro aparecen en diversos folios, así un tal don Tomás Mate, quizá la misma persona que aparece en un documento de $1814^{3}$. También don Félix Villamil Navajas y Hermoso, poseedor del libro a las alturas de 1821, porque así lo hace constar en la hoja anterior a la portada: "Soy de D. Félix Villaamil Navajas y Hermoso, 1821", que tal vez sea la misma persona que un tal Félix Villamil que poseía licencia para imprimir el Eusebio de Montengón, que había editado en 1807 en Madrid (Imprenta de Benito García). En 1831 pedía licencia para imprimir la misma obra en dos tomos [González Palencia, 1935: 345].

Ramillete divertido se compone, como decimos, de veinticuatro entremeses, pero uno de ellos, el titulado El embajador turbado (número 6), no es sino una broma de 10 versos, que parodia una comedia, al estilo de otras obritas de este corte ya conocidas. Salvo la dicha, el resto de los entremeses pertenece a algunos de los grandes entremesistas del XVII (Benavente, Calderón, Moreto, Cáncer, Matos, Avellaneda, Villaviciosa, Zamora...), aquí representados, aunque sus piezas figuran sin atribución; pero hay también otros ejemplos

3. Señor Don Tomas Mate, Don Fernando de Ibarrola y Don Ramon Prieto y Ortega, vecinos de esta corte y como apoderados de los demás interesados hasta el número de quarenta... se atreven a molestar... la... atención de V.M... y que será oida y atendida la justicia con que se consideran en un asunto... Los interesados en este... recurso... lo son por diferentes adquisiciones... de capitales impuestos en los cinco gremios mayores de esta corte...[Madrid, 1814]. Catalogo Colectivo del Patrimonio Bibliográfico Español. 
de obras que siguen el molde de las que se cultivan en el XVIII (como el entremés de chascos, comos o burlas).

Un número importante de entremeses de esta nueva colección es desconocido del todo, otros los conocemos por una versión diferente, aunque comparten título, personajes y argumento con las piezas contenidas aquí. Otros ofrecen variantes textuales con los entremeses conocidos. Los enumeramos a continuación, con la expresión de los folios que ocupan en el manuscrito, su primer y último verso y el censo de personajes que intervienen, con algún breve comentario añadido ${ }^{4}$ :

1. Hombre solo, El

ff. $1-9 \mathrm{v}^{\circ}$

Emp.: $\quad$ Usted me ajuste mi cuenta.

Acaba: tomen mi recibo en cuenta.

Personajes: Lorenzo, Vejete, Hombre solo, seis mujeres, un estudiante, tres hombres, un niño.

Com.: La Barrera recoge solo el título. En la BMM aparece como $E l$ hombre solo y criado escarmentado.

2. Calzones, Los

ff. $10-16$

Emp.: $\quad-$ Perdido está ya esto. - Y rematado.

Acaba: $\quad$ son mucha gente.

Personajes: Alcalde, molinero, escribano, sastre, zapatero, Matea, un muchacho.

Com.: La Barrera cita otro distinto con este título.

3. Colas, Las

ff. $17-24$

Emp.: $\quad$-Fuera digo, escribén. -Alcalde amigo.

Acaba: pues agarraldo todos por la cola.

Personajes: Alcalde, escribano, alguacil, una mujer, carpintero, herrador, dos niños.

Com.: Copia de 1776 en la BMM.

4. Alcaldes encontrados, Los

ff. $24 \mathrm{v}^{\circ}-30 \mathrm{v}^{\circ}$

Emp.: $\quad$ No me tenga, escribano, no me tenga.

Acaba: lo que ha venido.

Personajes: Mojarrilla, Domingo, mesonera, una moza, escribano, un preso.

4. Utilizo las siguientes abreviaburas: BNE (biblioteca Nacional de España), BBMP (Biblioteca Menéndez Pelayo de Santander), HSA (Biblioteca de la Hispanic Society of America), BMM (Biblioteca Histórica Municipal de Madrid) 
Com.: Es el entremés titulado así, primera parte, de Luis Quiñones de Benavente, aunque no acaba igual que la versión de este manuscrito.

5. Gansos, Los

ff. $31-36$

Emp.: $\quad$ Benita, no os canséis, que no heis de ir sola.

Acaba: a muchos gansos.

Personajes: Benita, gracioso, tres licenciados, un hombre, un valiente.

Com.: De Avellaneda, se publica en Verdores del parnaso, 1668. Se publica también en la Arcadia de entremeses, de 1691 y 1700, pp. 150-158. Se conserva también en un ms. de la Biblioteca Rodríguez Moñino, fechado en 1719, ms. 6913 [Cienfuegos, 2006: 484]. La versión de nuestro manuscrito cambia algunas lecturas de la que se recoge en Verdores y sustituye también el baile final por otro.

6. Embajador turbado, El

f. $36 v^{\circ}$. Lo transcribo íntegramente:

Unos: $\quad$ ¡Viva Persia!

Otros:

Otros:

¡Viva el Turco!

Turco: ¡Hola! ¿Qué ruido es aquel? (Sale.)

Criado: $\quad$ Es, gran señor, que ha llegado

el embajador de Persia.

Turco: Id, conducidle a palacio. (Salen todos ridículos y el embajador con una carta en la mano.)

Embajador: $\quad$ Yo, señor, si cuando...

Turco: Hablad.

Embajador: $\quad$ No puedo, que estoy helado.

Todos: $\quad$ Y aquí acaba el entremés

Fin

del embajador turbado.

Personajes: El Gran Turco, el embajador, un criado, acompañamiento.

Com.: Véase el comentario supra.

7. Celosa, La

ff. $37-43$

Emp.: $\quad$ Don Plácido, dejadme, que reviento

Acaba: $\quad$ sale de juicio.

Personajes: Don Plácido, Isabelilla, don Lesmes, tres mujeres, doña Bárbula, vecinos.

Com.: Es La barbuda, primera parte, atribuido a Calderón, aunque termina de diferente manera. Se representó en el corpus de 1664. Se recoge a nombre de Melchor Fernández de León (Obras., ms. 18331 
de la BNE, de 1689) y se publica en la Floresta, de 1680, como anónimo. También anónimo en un ms. de Osuna (BNE) de fines del XVII, ms. 16759, en el que también se titula La celosa [Lobato, 1989: 519-520]. Este manuscrito parece ser la fuente del nuestro, pues copia de él un pasaje que cambia la versión publicada en 1680 .

8. Tembleque

ff. $43 v^{\circ}-48 v^{\circ}$

Emp.: Válgame Dios, con qué grande cuidado

Acaba: salid, metemuertos crueles.

Personajes: Compadre, Tembleque, vejete.

Com.: Otra copia ms. en la HSA. Se imprime suelto (Madrid: Quiroga, 1792). Termina de diferente manera.

9. Tío y el sobrino, El

ff. 49-54

Emp.: $\quad$ Dejadme, amigas, que probar intento

Acaba: de aquesta suerte.

Personajes: Vejete, el sobrino, Marimocales, mujer $1^{\mathrm{a}}$, mujer $2^{\mathrm{a}}$, el tío.

Com.: Otra copia ms. en la BNE.

10. Guitarra, La

ff. $54 v^{\circ}-60 v^{\circ}$

Emp.: $\quad$ Compadre don Fermín, yo os he llamado.

Acaba: que hablen guitarras.

Personajes: Don Fermín, gracioso, graciosa.

Com.: Se publica en la Arcadia de entremeses, de 1700, pp. 56-58.

Suelto (con el Baile de la universidad de amor). BMPS.

11. Perezoso, El

ff. $61-66 v^{\circ}$

Emp.: $\quad$ Ea, acabad, Bartolo, simplonazo.

Acaba: $\quad$ este retablo se ha deshecho a palos.

Personajes: Bartolo, un letrado, Marina, un estudiante, alcalde.

Com.: Otro distinto con el mismo título en la BNE.

12. Jarro, $E l$

ff. $67-72 v^{\circ}$

Emp.:

Seor colega, no hay blanca.

Acaba: cuatro caballeritos aficionados.

Personajes: Un licenciado, un capitán, un alguacil, un valiente, Toribillo, la medidora.

Com.: De Antonio de Zamora, se publica en Comedias nuevas, de 1722, ff. 151-156, entre la primera y segunda jornada de El hechizado por fuerza. 
13. Visita y pleito de la liebre, La

ff. 73-78.

Emp.: -Amigo Alcalde. -Regidor amigo.

Acaba: a él y nadie cortesía guarde.

Personajes: Vejete, alcalde, un arriero, dos cazadores, un hombre, escribano.

Com.: De Francisco de Castro, se publica en Alegría cómica, de 1702.

14. Sombra, La

ff. $78 v^{\circ}-86 v^{\circ}$

Emp.: -Benito amado. - ¿Qué hay, compadre amigo?

Acaba: $\quad$ se quedará a la demanda.

Personajes: Benito, Aldonza, Chinela, compadre.

Com.: Otra copia en la BNE. Suelto (Sevilla: J. Padrino, s.a.). Biblioteca Navarra Digital.

15. Sí, El

ff. $87-93 \mathrm{v}^{\circ}$

Emp.: $\quad$ Amigo, ya el noble oficio

Acaba: no sé yo el fuego.

Personajes: Dos ladrones, una mujer, Vejete, Teresa (criada), un armonedero (sic).

Com: De Jerónimo de Cáncer y Velasco. Se publica en Autos sacramentales con cuatro comedias nuevas, con sus loas y entremeses (Madrid: María de Quiñones, 1655, ff. 195-198). Lo refunde Villaviciosa como El sí y la almoneda, ms. de 1692 de Osuna (BNE).

16. Cabeza encantada, La

ff. $94-100$

Emp:: $\quad$ Bartolo, ¿tú tan lucio y afligido?

Acaba: $\quad$ pues quedo novio.

Personajes: Bartolo, un pleiteante, un boticario, Andrea, Vejete, Hombre $1^{\circ}$ y Hombre $2^{\circ}$

17. Don Gorreta

ff. $100-104 v^{\circ}$

Emp.: $\quad$ Esto ha de ser, mi doña Dorotea.

Acaba: no he hallado mesa.

Personajes: Don Cosme, doña Dorotea, don Gorreta, Agustina, tres mujeres, graciosa.

Com.: De Matos y Villaviciosa. Se publica como El detenido en Laurel de entremeses, 1660. También es conocido por los títulos de Don Calceta, El entretenido don Calceta y El detenido don Calceta [Lobato, 2003: 91-109]. Se publica también en el Teatro español, de 
García de la Huerta, IV, pp. 61-75, en una versión que añade cuatro versos a la de nuestro ms. También suelto (Sevilla: José Padrino, s.a.).

18. Leche, La

ff. $105-111$

Emp.: $\quad$ idos de casa, andad, desvergonzados.

Acaba: $\quad$ se me ha vuelto.

Personajes: Bartolo, Vejete, Tomás, María, Carlos.

19. Francés, El

ff. $112-117 \mathrm{v}^{\circ}$

Emp.: $\quad$ Desesperado estoy, Francisca amiga.

Acaba: son castellanos.

Personajes: Toribio (gracioso), Palomino, Clara (graciosa), Francisca, don Juan.

Al fin: Compuesto por don Félix Villamil Navajas y Hermoso.

Com: De Jerónimo de Cáncer y Velasco. Se publica en Flor de entremeses, 1686, pp. 210-217. También suelto (Valladolid: Alonso del Riego, s.a.). BMPS.

20. Campanilla, La

ff. $118-122 v^{\circ}$

Emp.: $\quad$ Mujer, ¿quieres dejarme?

Acaba: de ser friolera.

Personajes: Escamilla, Manuela, don Braulio, un sastre, Valien te $1^{\circ}$, Valiente $2^{\circ}$, doña Rapia, doña Elena, una dama, un galán.

Com: De Agustín Moreto. Se publica a su nombre en Floresta de entremeses, 1691, pp. 20-27 y en Manojito de entremeses, 1700, pp. 10-17 y también como suelto (Sevilla: Diego López de Haro, s.a.). [Lobato, 2003] $]^{5}$.

\section{Cornudos, Los}

ff. 123-128

Emp.:

¡Ay de mí, que me mata mi marido!

Acaba:

ah, mandrias.

Personajes: Ventero, Aldonza (su mujer), don hombres (uno Juan de Aprieta), un propio.

5. Nuestra versión ms. aporta alguna variante con respecto a los otros testimonios, que parece obedecer a la adecuación con la fecha de representación, así suprime la voz ongarina o sustituye brahón por calzón. Elimina también algunos versos (vv. 29-30) y sustituye otros, como los 148-152, que cambia por otro: "la bolsa está a tu obediencia". Respeta, sin embargo, el nombre de los actores, lo que parece indicar copia de alguno de los impresos señalados arriba. 
Com.: Se tituló también Los dos cornudos en uno y Los cornudos y Juan de Aprieta, Juan de Aprieta y el chasco de la carta. Ninguno de estos responde a la misma versión que recoge nuestro ms.

22. Enmendador, $E l$

ff. $128 \mathrm{v}^{\circ}-134 \mathrm{v}^{\circ}$

Emp.: $\quad$ Alcalde furibundo, ¿a dónde vais?

Acaba: que no le creo.

Personajes: Alcalde, sargento, beata, escribano, regidor, graciosa, barbero, un golilla, un gallego, un hombre.

Com.: De Bartolomé Ibáñez, se publica en Chistes del gusto, 1742, pp. 719-720. También en un suelto del s. XVIII, que no acaba igual que la versión de este ms.

23. Burla de Pablillo, La

ff. $135-140 \mathrm{v}^{\circ}$

Emp.: $\quad$ ¿Qué desvergüenza es esta? Hola, criados.

Acaba: desta suerte se paga la soldada.

Personajes: Pablillo, vejete, mayoral, mujer.

Com.: Distinto del que se titula El espejo y la burla de Pablillos.

24. Doña Lamprea

ff. $141-148 \mathrm{v}^{\circ}$

Emp.: $\quad$ Amigo, deteneos. ¿Hay tal treta?

Acaba: contra la montaña, guerra.

Personajes: un montañés, Zumaque, un negro, doña Lamprea, un sargento, mujeres, hombres, música.

Como se puede apreciar, en general piezas del siglo XVII y otras que se recogen en antologías de principios del XVIII.

\section{Entremeses y otras obras cómicas inspiradas en el Quijote}

Las imitaciones, continuaciones o parodias del Quijote son muy frecuentes, tanto en lo que se refiere al teatro breve como el extenso, ya dentro del propio siglo XVII [Cotarelo, 1901; La Grone, 1937; Pérez Capo, 1947; Jurado, 2005]. Dejando aparte la oportunidad de incluir entre ellas el famoso Entremés de los romances (primera edición 1611 o 1612), hay que mencionar aquí el muy temprano Entremés de los invencibles hechos de don Quijote (1617), de Francisco de Ávila (1617), y otros que se representaron después, como $\mathrm{El}$ ventero (c1630), de Quiñones, también conocido como Lo que pasa en una venta, y atribuido a Belmonte Bermúdez [Madroñal, 1996: 105]; El hidalgo (c1637), probablemente de Solís o Las aventuras de Pascual del Rábano, entre otros muchos títulos de que también nos hemos ocupado recientemente 
[Madroñal, 2005]. Algunos de estos entremeses y otros de principios del XVIII se basan en episodios de la novela. Así el citado de Francisco de Ávila, que dramatiza la llegada de don Quijote y Sancho a la venta donde el ventero socarrón le arma caballero, el episodio del arriero que va a dar agua a sus bestias y la posterior paliza que recibe de este don Quijote, para terminar la pieza con una especie de boda burlesca en la que Marina, criada del ventero, finge ser Dulcinea. Ávila se basa en los capítulos 2 y 3 de la primera parte, pero añade hecho de su invención con intención paródica. En el entremés $E l$ ventero, también se escoge el tema de la venta, ahora asociado al episodio folklórico de la comida fantasma. Por su parte, en el Entremés de don Quijote, de Nuño Nisceno Sutil (1709), también se escoge como marco de la acción la visita de don Quijote y Sancho a una venta, en este caso la de Maritornes, donde se encuentra también Maese Pedro. Pero ahora la acción está mucho más adelantada: don Quijote ha estragado ya los cueros de vino del ventero y ha destrozado los títeres de Maese Pedro, y ahora todos fingen una burla para castigar al caballero: tienen que desencantar a unas fingidas princesas enfrentándose a un gigante llamado Gilote; pero en su lugar se enfrentan a un toro y a un diablo que los derriban por el suelo y todo acaba en canto y baile [Madroñal, 2008].

En otras piezas hay simples influencias más o menos importantes de la gran novela cervantina, así en La paga del mundo de Quiñones se alude a la inmortal pareja; también en El hidalgo, entremés en dos partes, de autoría disputada [Serralta, 1998], Juan Rana tiene una relación importante con Sancho; lo mismo ocurre con los titulados El ventero o El remediador, ambos de Benavente [Madroñal, 1996]; Los cuatro toreadores, de Francisco de Castro pone de manifiesto la relación con el escudero, al resaltar su cobardía; similar también es El rey de los tiburones, por cuanto recuerda el episodio del doctor Pedro Recio de Tirteafuera, como también el titulado El visir de la perdularia; en el Don Guindo, de Quirós, un figurón ridículo, trasunto de don Quijote, miente desaforadamente y se le aparecen damas barbadas y el lavatorio con trapos sucios. Y en otras es su escudero el protagonista, así un Sancho Panza, "muy gordo" aparece en el Entremés del astrólogo médico (1634), de Ordóñez de Ceballos, que acude al astrólogo porque ha perdido su burra y porque le han propuesto ser médico y gobernador de un hospital [Valladares, 1998]. Interesante también, pero mucho menos conocido, es el Entremés del segundo don Quijote y caballero de Meco, tal vez de 1656, igualmente manuscrito pero en él la única relación que encontramos con la novela cervantina es que su protagonista, Juan Quijote, que aparece "armado de coleto y pistolas". Se trata de una pieza de colegio que se desarrolla justamente en el ámbito escolar, cuyo argumento gira en torno al robo de provisiones de los escolares del colegio y la restitución de lo robado por amenaza de excomunión.

La evolución del Quijote en el teatro del siglo XVIII, tanto en el teatro breve como en otro tipo de piezas, es también muy conocida [Montero Regue-

6. Ms. 17505 de la BNE, ms. al parecer con letra del s. XVII. 
ra, 1993]. Baste sugerir aquí algunos títulos que pueden dar idea: El Alcides de la Mancha y famoso don Quijote (c1750), de Rafael Bustos Molina, que escoge para dramatizar los sucesos de la venta y las aventuras de Cardenio y Dorotea; también Ramón de la Cruz compuso un sainete titulado precisamente Don Quijote, aunque hoy perdido, al parecer, que suscitó la controversia del Sainete nuevo, apelación que hacen los poetas del Quijote juicioso al Quijote sainetero (1769), de Manuel del Pozo; curiosamente el episodio de las bodas de Camacho suscita la composición de varias obras como Las bodas de Camacho (c1770), de Antonio Valladares, que se subtitula "Comedia nueva jocoseria en dos actos", la zarzuela del mismo título que se debe a Leandro Ontala y Maqueda y Las bodas de Camacho el rico, de Meléndez Valdés (1784), de fracaso estrepitoso, y otras que también pertenecen al teatro breve, como Las caperuzas de Sancho (p1776). A todo ello habría que sumar la manuscrita Aventuras de don Quijote y religión andantesca, que se basa en el episodio de Luscinda-Dorotea, y la "comedia pastoral en cinco actos", también titulada Las bodas de Camacho [Montero Reguera, 1993, pp. 125-126].

Pero hay otras obras: no hace muchos años se nos daba noticia de algunas piezas cortas de inspiración cervantinas, que sin embargo no se han aprovechado convenientemente. Me refiero a entremeses del siglo XVIII que, a pesar de estar descritos por autores como Paz y Melia (en el caso del primero) no se han estudiado ni editado como conviene. Ambos, que se deben al mismo autor de mediados del XVIII ponen en escena dos episodios claramente apegados al texto novelesco, como son el del carro de Merlín y el de Clavileño, que parecen seguir el esquema de la comedia de González Barcia, por cuanto se apartan muy poco del modelo que había impuesto Cervantes en su obra. El primero de ellos, titulado Pasaje del carro de Merlín (de la historia de don Quijote) presenta la burla que hacen los duques a don Quijote y Sancho, en la que aparecen disfrazados de Merlín o el diablo varios personajes, que imponen los tres mil azotes a Sancho para desencantar a Dulcinea y el escudero acaba aceptando dárselos, con lo que termina la obra ${ }^{7}$; en el segundo, el titulado La burla del Clavileño y trova de don Quijote es el episodio del caballo de madera el que se escenifica para liberar de las barbas a la Trifaldi con sus damas. Don Quijote convence a su escudero para subir sobre el caballo y le pide que se dé algunos azotes; pero este se niega argumentando que entonces no podrá sentarse. El entremés acaba como lo hace el episodio en la novela, con el vuelo del caballo por los aires y la caída del caballero y su escudero por los suelos de [De Miguel Reboles, 2002]. No resulta fácil precisar cuándo se escribieron estas dos piezas, que a todas luces parecen autógrafas. Detalles como la letra y algunas palabras parecen aconsejar que se sitúen en la centuria dieciochesca, pero por el momento no podemos precisar más.

Mucho más interesante es otro entremés que se titula Sancho Panza en el gobierno de la ínsula Barataria, igualmente manuscrito, que parece que

7. BNE ms. 14600-11, ff. 1-4vo . Paz y Melia no advirtió que inmediatamente detrás, ff. 5-10 figuraba el segundo entremés: Pasaje del carro de Merlín de la historia de don Quijote. 
se compuso para representarse con la comedia de Pedro Ruiz de la Osa, La serenidad de un día y confesión de una noche, que se hizo para conmemorar la boda de la marquesa de Villena (doña María Ana López Pacheco), en $1748^{8}$. En este entremés se envía a Sancho Panza, "hombre muy ridículo", a la ínsula del duque para que le divierta con los chascos correspondientes, ante la falta de "danzantes y mojigangeros, que es lo que ahora se usa"9 . Sancho, que tiene como asesor a su rucio y aparece con su mujer (se advierte en el ms. que su papel lo hará un hombre) enjuicia varios asuntos que se le plantean, que no corresponden con los que aparecen en la novela cervantina (un herrador, una vellera, el doctor Pedro Recio de Tirteafuera...) y, al final, los enemigos atacan la ínsula, se arma grotescamente a Sancho, que muestra la misma cobardía que en la novela, y todo termina con que se quiere volver a la Mancha, porque prefiere su libertad a los sustos que dan las tareas de gobierno.

Y así llegamos a la pieza que nos ocupa hoy: La cabeza encantada, pieza desconocida para los estudiosos, por cuanto falta en todos los catálogos de entremeses consultados.

\section{De cabezas encantadas en la literatura y el capítulo 62 de la segunda parte del Quijote. El entremés de La cabeza encantada}

El asunto de la cabeza encantada que aparece en el capítulo 62 de la segunda parte del Quijote ya lo había llevado al teatro Juan Ruiz de Alarcón en La cueva de Salamanca, donde se utiliza para dar un susto a un gorrón de aquella Universidad, que presumía de saber todo.

$\mathrm{Su}$ origen es remoto: para algunos estudiosos el episodio aparece ya en un libro de caballerías francés, Valentin et Orson, de 1489, que se vierte al italiano en 1557. Se conoció en España y, entre otras cosas, inspiro a Lope de Vega su comedia con el mismo título, Ursón y Valentín, donde sin embargo no aparece la referencia a la mágica cabeza [Alvar, 2006: 1620-22]. Francisco Rico, en las notas complementarias a su edición del Quijote señala que la anécdota de la cabeza encantada pudo recogerla Cervantes de Girolamo Cardano, que apareció en la obra de Jacob Wecker De secretis (1592); pero apunta también que se atribuía a san Alberto Magno la invención de una cabeza parlante, como recoge por primera vez en España el Tostado [Rico, 2004, II: 629-630].

Otros estudiosos recuerdan su vinculación con la leyenda referida a don Enrique de Villena, que también tenía que ver con una "cabeza encantada"; registra igualmente una referencia al mismo prodigo Antonio de Yepes en su Crónica de san Benito (1609), donde menciona otra leyenda relacionada con

8. Todo se encuentra contenido en el ms. 14867 de la BNE, manuscrito con letra del s. XVIII. Contiene también una loa inicial y el Baile del barón de Perales del Río. Preparo edición de este breve corpus entremesil relacionado con el Quijote.

9. Ms. cit., f. 51. 
el papa Silvestre II, el cual, poseía un libro que había robado a otro mago que le había permitido confeccionar una cabeza de plata que adivinaba el futuro [Bubello, 2009].

El caso es que en el Quijote, Sancho y su amo consultan a una cabeza encantada que tenía en su casa el caballero barcelonés don Antonio Moreno, el cual había ideado un truco para burlarse de los crédulos personajes, por medio del cual un sobrino suyo emitía la voz que supuestamente salía de la cabeza. Por supuesto, la burla consigue su propósito y el narrador nos informa de que caballero y escudero siempre creyeron en el carácter mágico de la cabeza, aun cuando se nos diga también que la Inquisición mandó que se destruyese para que los crédulos e ignorantes no siguiesen pensando en algo tan peligroso como todo lo que tenía que ver con la adivinación y los agüeros.

A diferencia de la novela, en el entremés que editamos a continuación, la cabeza encantada la trae un matemático italiano, sin duda en referencia a la fama que tenían estos como portadores de otros prodigios mecánicos con que parecen una y otra vez en los entremeses de finales del XVII: concretamente los mundinovi o tutilimundi, unos ingenios similares a los títeres que se ofrecían en una especie de caja mágica con unas lentes y que causaban la admiración del público. Este tipo de piezas, como la Mojiganga del mundi novo de Calderón y otras coinciden con la que nos ocupa (la cabeza encantada) en que son o fingen ser inventos que se traen a España, casi siempre por parte de los italianos o de personajes que fingen ser italianos y hablan una lengua a medio camino entre el español y el italiano.

Sin embargo, nuestro entremés escoge un motivo de éxito seguro en el teatro, el de las cabezas que adivinaban el futuro, como ocurre en el citado capítulo 62 del Quijote. Solo que en la obrita dramática el asunto de la cabeza es una burda estratagema para que el gracioso Bartolo pueda ver a Andrea, la hija del celoso Vejete. Un amigo se finge matemático italiano que ha traído el portento de la cabeza adivinadora, dentro de la cual (y de una mesa) se ha escondido el gracioso, que disparata ante las preguntas que le hacen el Vejete y sus amigos, el pleiteante y el boticario. El descubrimiento de la incapacidad de adivinar de la cabeza trae el aporreo de Bartolo, pero al final se descubre todo y el Vejete le permite que se case con su hija. Un baile final con seguidillas termina la obra.

Una ficción, como otras muchas que aparecen en los entremeses del XVII, para facilitar la entrada del enamorado en casa de su amada. Recordemos por ejemplo piezas como el Entremés nuevo de los sacristanes, de Quiñones, en que estos personajes se fingen fuelles para poder entrar en casa del viejo que guarda a sus dos hijas, el cual termina aporreando a los pretendientes, aunque se concede la boda al final [Madroñal, 1996: 169-184]. Exactamente igual que en el presente entremés, que se basa sin duda en este tipo de piezas.

Pero hay algunos versos que parece remitir al Quijote, porque allí se dice que la cabeza encantada es de bronce, igual que en la pieza que ahora editamos, y que tiene la "virtud de responder a cuantas cosas al oído le preguntan" 
[Cervantes, 2004, II: 1023], lo cual parece relacionarse con lo que se dicen en nuestro entremés de la cabeza:

Esta, a cuanto le preguntan, como al oído le hablen, responde elegantemente" (vv. 103-105)

La métrica es bastante simple: el entremés se compone de 202 versos, de los cuales:

1-66: silva de endecasílabos.

67-112: romance.

113-198: silva de endecasílabos.

199-202: seguidillas

Lo que arroja el porcentaje siguiente:

$152 \mathrm{vv}$. silva de endecasílabos $=75,24 \%$ ( $13 \mathrm{vv}$., un $8,55 \%$, quedan sin rima).

46 vv. romance $\quad=22,77 \%$

4 vv. seguidillas $\quad=1,98 \%$

TOTAL 202 vv. $\quad=100 \%$

\section{Criterio editorial}

Transcribo el manuscrito citado, ff. 94 a 100, y actualizo las grafías sin valor fonológico. Modernizo todo lo relativo a la acentuación, puntuación y mayúsculas según los criterios últimos de la Real Academia Española. Mantengo como están las palabras en el supuesto italiano que utiliza uno de los personajes.

\section{BIBLIOGRAFÍA}

Abrams, Fred: «Pedro Noriz and Tirso de Molina in the Enchanted Head Episode of the Quijote», Romance Notes, X (1968), pp. 122-128.

Aguilar Piñal, Francisco: Bibliografía de autores españoles del siglo XVIII, Madrid: CSIC, 1981-2002.

Alvar, Carlos (dir.): Gran Enciclopedia Cervantina, tomo 2, Madrid, Castalia-Centro de Estudios Cervantinos, 2006.

Avalle Arce, Juan Bautista: «La cabeza encantada (Don Quijote, II, 62)», Homenaje a Luis Alberto Sánchez, ed. de R.G. Mead, Madrid: Ínsula, 1983, pp. 49-53.

Arellano, Ignacio (coord.): Don Quijote en el teatro español del siglo de Oro al siglo XX. Madrid: Visor, 2007. 
Bubello, Juan Pablo: "La cabeza encantada", risa y polémicas antimágicas en el "Quijote de la Mancha". En Gonzalez, MaríaLuz, (comp.), Historia Moderna. Viejos y nuevos problemas, Mar del Plata, Universidad Nacional de Mar del Plata-Eudem, 2009, pp. 101-112.

Cervantes, Miguel de: Don Quijote de la Mancha. Barcelona: Círculo de Lectores-Galaxia Gutenberg, 2004.

Cienfuegos Antelo, Gemma: El teatro breve de Francisco de Avellaneda: estudio y edición, Madrid, Fundación Universitaria Española, 2006.

Cotarelo y Mori, Emilio: "Las imitaciones castellanas del Quijote", en Estudios de historia literaria de España, I. Madrid, Imprenta de la Revista Española, 1901, pp.71-100.

---Colección de entremeses, loas, bailes, jácaras y mojigangas. Estudio preliminar e índices de José Luis Suárez García y Abraham Madroñal. Granada: Universidad de Granada, 2000.

De Miguel Reboles, María Teresa: Homenaje al Quijote. Pasaje del carro de Merlín y otras obras. Madrid: Asociación Universitaria Medievalense, 2002.

Don Gil de la Mancha. Ed. Pedro J. Isado. Prólogo de Felipe Pedraza. Madrid: Diputación de Ciudad Real, 2002.

Fernández Gómez, Juan: Catálogo de entremeses y sainetes del siglo XVIII. Oviedo: Instituto Feijoo del siglo XVIII, 1993.

García Lorenzo, Luciano (ed.): Don Quijote de la Mancha, de Guillén de Castro. Madrid: Anaya, 1971.

García Martín, Manuel: Cervantes y la comedia española en el siglo XVII. Salamanca: Universidad de Salamanca, 1980.

---(ed.): El hidalgo de la Mancha, de Juan de Matos Fragoso, Juan Bautista Diamante y Juan Vélez de Guevara. Salamanca: Universidad de Salmanca, 1982.

González Palencia, Ángel: Estudio histórico sobre la censura gubernativa en España. Madrid, Tipógrafa de Archivos, 1934-1935.

Jones, Joseph, "Historical materials for the Study of the Cabeza Encantada episode in Don Quijote. II.62." en Hispanic Review, 47 (1979), pp. 87-103.

Jurado Santos, Agapita: Obras teatrales derivadas de novelas cervantinas (siglo XVII). Para una bibliografia, Kassel: Reichenberger, 2005.

Kallendorf, Hilaire, “'Why The Inquisition Dismantles The 'Cabeza Encantada'?”, en Anuario de Estudios Cervantinos, I, (2004), pp. 149-164.

La Barrera, Cayetano Alberto de: Catálogo bibliográfico y biográfico del teatro antiguo español, desde sus origenes hasta mediados del siglo XVIII, Madrid, 1860.

Lagrone, Gregory Gough: The imitations of "Don Quixote" in the Spanish Drama. Philadelphia, University of Pennsylvania, 1937.

Lobato, María Luisa (ed.): Teatro cómico breve de Pedro Calderón de la Barca, Kassel: Reichenberger, 1989.

---Loas, entremeses y bailes de Agustin Moreto, Kassel: Reichenberger, 2003.

Madroñal, Abraham: Nuevos entremeses atribuidos a Luis Quiñones de Benavente. Kassel: Reichenberger, 1996.

---“Entre Sancho Zancas y Juan Rana”, en Luciano García Lorenzo (dir.): La construcción de un personaje: el gracioso. Madrid: Fundamentos, 2005, pp. 245-298.

---"Entremeses intercalados en el Quijote", en Miguel Ángel Garrido Gallardo y Luis Alburquerque (eds.): El Quijote y el pensamiento teórico-literario. Madrid: CSIC, 2008, pp. 265-277.

---“El olvidado Entremés de don Quijote, de Nuño Nisceno Sutil”, en Anales Cervantinos, XL (2008), pp. 311-332. 
Montero Reguera, José: "Imitaciones cervantinas en el teatro español del siglo XVIII", en Actas del tercer coloquio internacional de la Asociación de Cervantistas, BarcelonaMadrid: Anthropos-Ministerio de Asuntos Exteriores, 1993, pp. 119-129.

Pérez Capo, Felipe: El Quijote en el teatro. Barcelona, Editorial Milla, 1947.

Reed, Cory A., "Ludic revelations in the enchanted head episode in Don Quijote (II, 62)" en Cervantes. Bulletin of the Cervantes Society of America, 24 (2004), pp. 189-216.

Rico, Francisco: Notas a la edición de Don Quijote de la Mancha. Barcelona: Círculo de Lectores-Galaxia Gutenberg, 2004.

Senabre, Ricardo: "Una temprana parodia del Quijote: Don Pascual del Rábano", Homenaje al profesor Orozco Díaz, III, Granada, Universidad de Granada, 1979, pp. 349-361.

Serralta, Federico: "El hidalgo- primera parte- entremés anónimo (¿de Solís?)”, en Crit, 27 (1987), pp. 203-225.

Valladares, Aurelio: “Aportación de Pedro Ordóñez de Ceballos al entremés del Siglo de Oro”, en Rlit, LX (1998), p. 393.

\section{ENTREMÉS LA CABEZA ENCANTADA}

\section{Personas}

Bartolo

Hombre $1^{\circ}$

Hombre $2^{\circ}$
Un pleiteante

Un boticario

Andrea

Vejete

Salen Bartolo y dos hombres

$1^{\circ} \quad$ Bartolo, ¿tú tan lucio y afligido, tan mustio, tan insulso y amarrido? ¿Qué tienes?

$2^{\circ}$

¿Qué te ha dado, que andas todo confuso y demudado? ¿Tienes cuñado, fondo en sabañones, o mujer que te espulga los calzones? ¿Es tu mal como aquestos que he contado?

BARTOLO Remuchísimo más. ¡Ay, desdichado!

$1^{\circ} \quad$ ¿Mayor desdicha ha sido?

Sin duda, has entrado a ser marido.

¿Qué va que sin saber cómo o por dónde te has metido a cochero de vizconde?

BARTOLO Aun es mayor mi injuria. 
Pues, cuitado, ¿qué viene a ser tu mal?

BARTOLO Estó preñado.

$1^{\circ} \quad$ ¿Preñado? ¿Hay más estraño desatino?

$2^{\circ} \quad$ ¿Qué dices, hombre? ¿Estás lleno de vino?

BARTOLO Digo que estó preñado.

$1^{\circ} \quad$ Tal no he visto.

BARTOLO ¡Así estuviera usted, pluguiera Cristo!

$1^{\circ} \quad$ ¿Qué dices?

BARTOLO Que a este lado tengo el engendro.

$1^{\circ} \quad$ (Es grande majadero.)

BARTOLO Mayor es que una copa de sombrero.

$2^{\circ} \quad$ A ver, ¿te has vuelto loco?

BARTOLO No me toquen. ¡Ay, Virgen !

No te toco.

$1^{\circ} \quad$ ¿No habrá quien le reporte?

BARTOLO ¿Mas qué quieren hacerme, que le aborte?

$2^{\circ} \quad$ No pretendemos tal; mas, hombre, dinos, si es que te dan lugar tus desatinos, por dónde tus enojos hicieron el engendro.

BARTOLO Por los ojos.

$1^{\circ} \quad$ Esa es duda más fuerte. 
Pues, ¿de qué suerte ha sido?

BARTOLO Desta suerte:

yo vi los otros días

la sobrina del viejo Matatías ${ }^{10}$

$\mathrm{y}$ aficioneme tanto a la doncella

que puse sin sentir el ojo en ella.

Desde entonces padezco un accidente

que rascándome estoy continuamente;

dícenme que es amor los más expertos,

mas yo jurara a Dios que eran entuertos.

Yo reviento por vella y por habralla, mas el viejo barbón es tan canalla que la vela y la guarda, y yo me muero de esta sarna con quien me desespero, porque ello, de deseo u de cuidado,

o estó borracho yo u estó preñado

y pues verla no puedo por mi ojo,

bien me podéis creer que ha sido antojo.

Cúmplamele, por Dios, vueso agasajo, así libres estéis de este trabajo.

$1^{\circ} \quad$ (A risa me provoco de escuchalle.)

$2^{\circ} \quad$ Calle, pobrete, que he de consolalle

con una nueva traza que he pensado.

BARTOLO ¿Cuál es?

$2^{\circ}$

Yo he de entralle disfrazado

donde vea la moza.

BARTOLO Hazlo y ponme después una coroza.

$2^{\circ} \quad$ He de decir que soy un italiano, matemático, diestro y soberano, que una cabeza traigo aquí encantada y que responde, en siendo preguntada. ¿Sabrás tú responder a cualquier cosa?

BARTOLO Sí sabré.

Pues tu suerte es ya dichosa.

10. Aquí se produce una incongruencia, pues más adelante se dice que es hija. 
$1^{\circ} \quad$ Yo ayudaré al enredo.

BARTOLO ¿No decís ahora más?

$2^{\circ}$

No, que no puedo.

$1^{\circ} \quad$ Vamos. Ya se han logrado tus amores.

BARTOLO Pues con esto cesaron los dolores. (Vanse.)

Sale el Vejete

VEJETE ¡Muchacha, Andrea, chiquilla!

¿Hay desvergüenza más grande?

¿No me oyes, niña?

ANDREA

¿Qué manda

vuesa merced, señor padre?

VEJETE Si ya me curé la fuente,

si ya me he puesto los parches, si estoy en traje de ir fuera, ¿por qué no vienes?, ¿qué haces?

ANDREA Estaba haciendo labor.

VEJETE ¡Qué humildad! Dios te depare

la dicha de cualquier tonto.

$1^{\circ}$

¡Ah de casa!

ANDREA

¿Quién es?

VEJETE

Abre.

$1^{\circ}$
¿Vive aquí don Camarroja
de Bisnaga Badulaque
Califurnio Catahígas
Rapachinches y Estoraque? 
ANDREA Aquí vive.

$1^{\circ}$

En hora buena.

$\mathrm{Al}$ aspecto vulnerable

de candidísimas canas,

con solidísimas frases, llega humildísimo afecto

al que integérrimo aplaude

las superplúrimas señas

de su estático semblante.

VEJETE (¡Jesús, y qué tarabilla!)

Tenga usted muy buenas tardes.

$1^{\circ}$ Señor mío, yo sabiendo

que gusta de novedades

y llegando a este lugar

el prodigio más notable,

vengo a ser quien le conduzca.

VEJETE Estimo el favor que me hace.

$1^{\circ} \quad$ Señor mío, un italiano

de Italia un prodigio trae

100

de una cabeza encantada.

VEJETE ¿Encantada dijo? ¡Tate!

$1^{\circ} \quad$ Esta, a cuanto le preguntan, como al oído le hablen, responde elegantemente.

VEJETE Prodigio es bien admirable.

$1^{\circ} \quad$ Conmigo viene.

VEJETE Pues que entre.

ANDREA Yo llamaré a quien la trae.

$1^{\circ} \quad$ (A Andrea.) (Oyes, el de la cabeza

es Bartolillo, tu amante,

que, por verte, este disfraz

ha tomado.) 
VEJETE Andrea, ¿qué haces ?

ANDREA. Nada. Entre usted.

Sale el Hombre $2^{\circ}$ vestido de italiano y se saca una mesa con una cabeza, por dentro de la cual sacará Bartolo la cabeza para responder.

$2^{\circ}$

Signor, bon giorno.

Entrate, mio fratelo, intorno, intorno, portate aquesta cosa.

VEJETE (Sin duda que esta alhaja es muy preciosa.)

ANDREA Padre, ¿qué es esto?

VEJETE Atiende a este portento.

$2^{\circ} \quad$ Tuto il mondo, signori, estate atento:

tuto il mondo ho girato

com questa maravilla

di qua dila in una e altra villa

tuti han fato terrible admiratione

di questo incanto a tutte le natione.

$1^{\circ} \quad$ (¡Pobre vejete, cuál te la han pegado!)

BARTOLO (¡Pobre de mí, que vengo aquí enjaulado!)

VEJETE ¿De suerte que, con ser de bronce hecha, como me dijo aquese caballero, responde esa cabeza prodigiosa?

$2^{\circ}$

Hablateli al oído qualque cosa.

ANDREA ¿Sí, padre?

VEJETE Yo quiero hacer la experiencia.

$1^{\circ} \quad$ (Ya a mi risa le apura la paciencia.)

VEJETE ¿Qué vendrá a ser de mí, que soy anciano, noble, rico, sin tacha ni mal vicio?

BARTOLO Vendrás a ser tostón del Santo Oficio. 
VEJTE ¡Jesús!

ANDREA (A eso el oráculo le obliga.)

$2^{\circ} \quad$ Oye vusté, pues mali es qui li diga.

VEJETE Sin aliento he quedado:

aguardad, llamaré desde el terrado

los vecinos, que vean lo que he visto. (Vase.)

BARTOLO (Sale de la cabeza.) ¿Fuese?

$2^{\circ}$

Sí, ya se fue.

BARTOLO Loado sea Cristo.

140

Divina Andrea, hermosa,

carita de clavel, pico de rosa, mira cómo parezco en tal tragedia degollado de paso de comedia.

¿No me pagas, amante, esta fineza?

ANDREA Sí, mi bien.

Vuélvenle a poner la cabeza y salen el Vejete, el Pleiteante y el Boticario.

VEJETE Venid. Pero, ¿qué es esto?

ANDREA Preguntando

estaba a la cabeza cierta cosa.

VEJETE ¿Y respondió?

ANDREA Una cosa bien graciosa.

VEJETE Pregúntale otra vez.

ANDREA $\quad$ Ya te obedezco: $\quad 150$

¿Cuándo seré dichosa? A ver si acierta.

BARTOLO En sacándote un ojo y quedar tuerta.

ANDREA ¡Jesús, qué pasmo! Dicha es sin fatiga. 
$2^{\circ} \quad$ Oye vusté, pues mali es qui li diga.

PLEITEANTE Hablarle de mis pleitos determino:

¿Cómo saldré de un pleito que mantengo

y es mi justicia franca?

BARTOLO Con doscientos azotes y sin blanca.

PLEITEANTE ¿Qué oigo? Tal agüero me atosiga.

$2^{\circ} \quad$ Oye vusté, pues mali es qui li diga.

VEJETE Aquí hay maula, señores, hablemos aquí aparte, que esto de esta cabeza es cosa de arte.

BOTICARIO Parece hechicería.

Hablan aparte, de espaldas a la cabeza, el Vejete, Pleiteante y Boticario. PLEITEANTE Absorto estoy.

$1^{\circ}$

Ahora.

BARTOLO (Saca la cabeza.) Vida mía, 165 centro del corazón, vente conmigo, que el alma está estrujada como higo por tu amor.

ANDREA Soy tuya, mi Bartolo.

$1^{\circ} \quad$ ¡La cabeza, que miran!

Vuelve a meterse.

VEJETE Esto solo se ha de hacer: llegue usted, seó Boticario. (Vase.) A la orella, que aquesto e necesario.

BOTICARIO ¿Dónde iré yo, cuando por bien del mundo mezclo el ruibarbo, acíbar y cerote?

BARTOLO Al infierno te vas de bote en bote. 
BOTICARIOEs mentira y la rabia me atosiga.

$2^{\circ} \quad$ Oye vusté, pues mali es qui li diga.

ANDREA Prodigio es la cabeza.

$1^{\circ} \quad$ No hay en lo descubierto mejor pieza.

Sale Vejete.

[VEJETE] Aparten. (Vive Dios, que lo pensado (Aparte.) me ha de sacar de duda). Yo he buscado estos papeles, por si al preguntalla

lo que dentro se halla dice aquesta cabeza.

Así conoceremos su destreza.

$2^{\circ} \quad$ (En ratonera nos cogió este viejo.) (Aparte.)

$1^{\circ} \quad$ (No doy tres cuartos hoy por mi pellejo.) (Aparte.)

BARTOLO (Vive Dios que la trampa ya es notoria.) (Aparte.)

VEJETE ¿Qué hay entre este papel de ejecutoria, donde están mis parientes y trofeos?

BARTOLO Hay una procesión de fariseos.

VEJETE Mientes, que es una piedra y darte espero.

BARTOLO ¡Tente, hombre, que me rompes la mollera!

Vale a dar y corre con la mesa al cuello, y luego sale y se pone de rodillas.

VEJETE ¿Qué es esto que estoy viendo?

BARTOLO Esto es, vejete mío, estar queriendo a tu hija divina ${ }^{11}$

y así lograrla el alma determina

\section{ANDREA Désela.}

11. Se ha tachado « amada sobrina » para escribir después las dos últimas palabras. 
UNA COLECCIÓN DE ENTREMESES INÉDITA Y DESCONOCIDA (CON LA EDICIÓN DE LA CABEZA...343

BARTOLO O voyme al punto a meter fraile.

VEJETE Cásense con el diablo, y va de baile.

ANDREA ¿Cómo con el encanto quedas, Bartolo?

BARTOLO Mucho peor que antes, pues quedo novio

Fin

Recibido: 8 de marzo de 2012

Aceptado: 15 de octubre de 2012 
$344 \cdot$ ABRAHAM MADROÑAL

\section{ILUSTRACIONES}

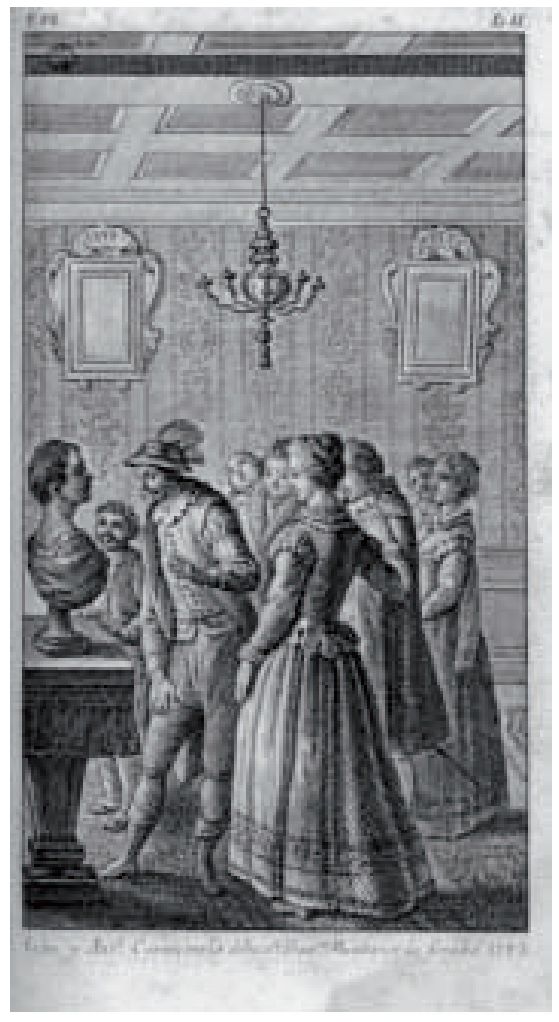

Ilustración del episodio en el Quijote según grabado de 1782. 
UNA COLECCIÓN DE ENTREMESES INÉDITA Y DESCONOCIDA (CON LA EDICIÓN DE LA CABEZA...345

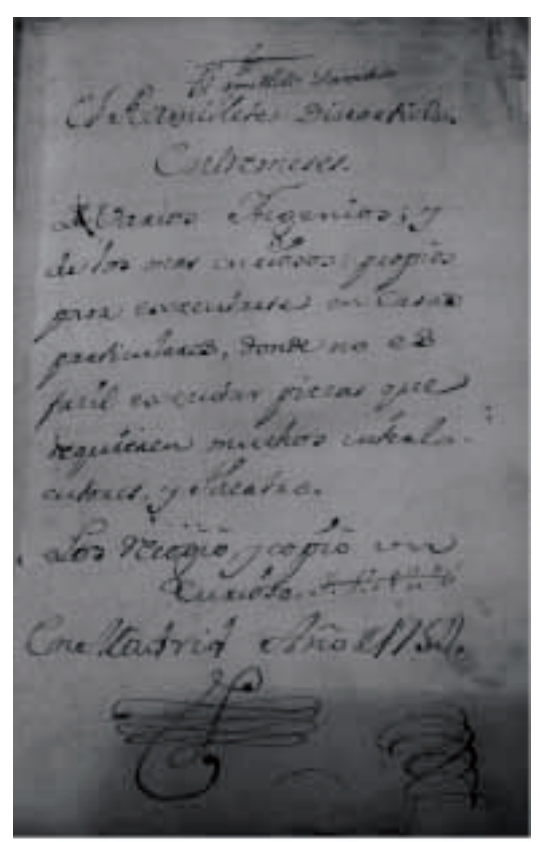

Portada del manuscrito Ramillete divertido.

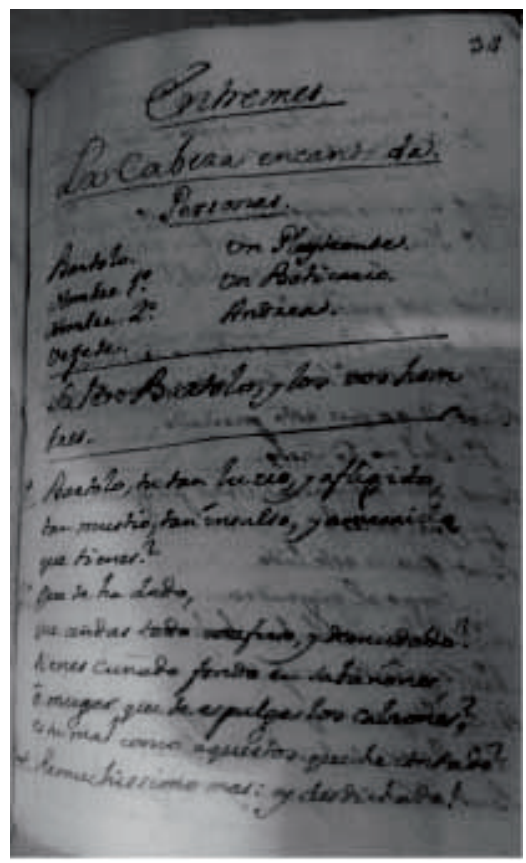

Inicio de La cabeza encantada. 